\title{
A Novel Intervention to Reduce Bronchoscopy Lab Costs
}

\section{Kevin P. Kane ${ }^{1}$, Jennifer W. Toth ${ }^{2}$, Michael F. Reed ${ }^{3}$ and Christopher R. Gilbert ${ }^{4 *}$}

${ }^{1}$ Pittsburgh Critical Care Associates, Inc., Swissvale, PA, USA

${ }^{2}$ Division of Pulmonary, Allergy and Critical Care, Penn State Milton S. Hershey Medical Center, Hershey, PA, USA

${ }^{3}$ Division of Thoracic Surgery, Penn State Milton S. Hershey Medical Center, Hershey, PA, USA

${ }^{4}$ Division of Thoracic Surgery and Interventional Pulmonology, Swedish Cancer Institute, Seattle, WA

\begin{abstract}
New endoscopic technology has advanced the field of bronchoscopy. With these innovations comes the increased price of maintenance and repair, and the current literature offers few interventions for reducing such costs. We identified increased maintenance costs despite standard physician and technician endoscopic training, which warranted further intervention. An on-site visit by an industry provided endoscopy support specialist team provided direct observation and feedback regarding daily operating procedures as well as bronchoscope handling, processing, and storage. Our intervention resulted in subsequent reduction of maintenance costs by $67 \%$. The use of endoscopy support specialists may help identify and implement daily practices that can reduce bronchoscopy maintenance and repair costs when endoscopy units are faced with unexpectedly high maintenance expenditures.
\end{abstract}

Keywords: Bronchoscopy; Bronchoscopy lab; Maintenance; Repair; Costs; Endobronchial ultrasound; Transbronchial needle aspiration

\section{Introduction}

Advancing technology has changed the diagnostic approach to diseases of the thorax. Newer generation bronchoscopes possess technological advances that include improved processing, visualization, and ultrasonic images; however these advances can be associated with increased damage and repair costs [1,2]. Medical institutions are under pressure to remain fiscally viable and increased expenditures appear associated with the presence of advanced bronchoscopy programs [26]. Internal education of endoscopy team members may help reduce costs [4-6] however institutionally specific circumstances may provide barriers to effective internal review.

Our financial review of bronchoscopy maintenance costs identified a projected budget deficit secondary to repair expenditures. In an effort to maintain an efficient, cost effective bronchoscopy program, we postulated that an external, objective, third party evaluation may provide an opportunity to identify areas of improvement not detected/ addressed on internal review. The aim of this manuscript was to describe the intervention and outcomes associated with the described intervention.

\section{Methods}

The discovery of perceived high bronchoscope repair costs prompted a roundtable discussion among bronchoscopists and bronchoscopy support staff (nursing, technicians, and leadership). This meeting resulted in an invitation for a manufacturer support team (MST), consisting of endoscopy support specialists, regional (service and sales) managers, and repair technicians to observe our daily bronchoscopy practices both within the operating theatre and endoscopy suites. Daily practice includes the utilization of both endoscopy and operating rooms in which three bronchoscopists (JWT, MFR, CRG) perform approximately 145 bronchoscopic procedures per month, with active involvement of pulmonary and surgical trainees. The Olympus Bronchoscope Platform (Olympus Inc., Center Valley, PA) is utilized for all flexible bronchoscopic procedures. The institution leased ten bronchoscopes (3-convex probe endobronchial ultrasound (CPEBUS) puncturescopes, 3-therapeutic bronchoscopes, and 4-diagnostic bronchoscopes) during the study period. These bronchsocopes are only utilized by the above bronchoscopists, and all bronchoscope set-up, cleaning, and storage is performed under the direction of specialized endoscopy technicians.
The MST was tasked to review all activities performed in a standard day, performing a "Repair Reduction Evaluation." This evaluation involved over 10 hours of direct observation, beginning with the setup of the first bronchoscopy of the day until the last bronchoscope was cleaned and stored for the day. Clinicians, nurses, technicians, and cleaning/processing staff were all observed. The MST utilized a 46-item checklist (online supplement, abbreviated in Figure 1). Feedback was then provided for all staff within 24 hours of the visit delivered in a lecture format, including detailed descriptions of each party's respective involvement in bronchoscope handling, with focus on areas of potential areas of improvement.

A particular concern identified by the MST was poor handling of the distal end or "tip" of the bronchoscope. As a particularly delicate component, cognizance of the scope's distal end location was stressed throughout its clinical use and maintenance phase. Utilizing MST recommendations, our endoscopy team embarked on a campaign dubbed "tip awareness". Education efforts included the afore-mentioned presentation as well as hands-on, directed instruction to all associated providers in the bronchoscopy suite. Concerted efforts were made to minimize distal end impacts, including pre-procedure on-deck bronchoscopes being appropriately placed in respective holsters on the bronchoscopy tower and laying the distal tip on a table with only a slight bend in the insertion tube. Tip awareness during post procedure transport, cleaning and storage was encouraged, including avoidance of pinch points, avoiding placement in holes within bronchoscope processing units, and particular attention during removal of scopes from cleaning units.

Our outcomes of interest included bronchoscope repair costs (October 2012-March 2014) and our performance on the Repair Reduction Evaluation. Damage costs were obtained from manufacturer issued invoices for damage repairs October 2012 to July 2013 (pre-

*Corresponding author: Christopher R. Gilbert, DO, MS, FCCP, Swedish Cancer Institute, 1101 Madison Street, Suite 900, Seattle, WA 98104, USA, Tel: 206-2156800; Fax: 206-215-6801; E-mail: christopher.gilbert@swedish.org

Received March 26, 2016; Accepted April 28, 2016; Published April 30, 2016

Citation: Kane KP, Toth JW, Reed MF, Gilbert CR (2016) A Novel Intervention to Reduce Bronchoscopy Lab Costs. J Pulm Respir Med 6: 339. doi:10.4172/2161105X.1000339

Copyright: $(2016$ Kane KP, et al. This is an open-access article distributed under the terms of the Creative Commons Attribution License, which permits unrestricted use, distribution, and reproduction in any medium, provided the original author and source are credited. 
Citation: Kane KP, Toth JW, Reed MF, Gilbert CR (2016) A Novel Intervention to Reduce Bronchoscopy Lab Costs. J Pulm Respir Med 6: 339. doi:10.4172/2161-105X.1000339

Page 2 of 3

intervention period) and again from July 2013 to March 2014 (intervention period). No institutional review board review was required due to lack of human subjects research.

\section{Results}

Bronchoscope repairs for pre-intervention period (October 2012July 2013) were $\$ 60,015$ (Table 1). Bronchoscope damage costs varied from laceration of the outer sheath $(\$ 275$, Figure 2$)$ to damage of the ultrasound probe/array (over $\$ 6000$, Figure 3). After the Repair Reduction Evaluation and recommendations were implemented in the intervention period (July 2013-March 2014), repair costs fell $67 \%$ to $\$ 19,950$. The majority of repairs in the intervention period appeared to involve bending section cover replacements, with minimal damage resulting from working channel or distal tip damage.

Feedback obtained from the Repair Reduction Evaluation indicated a deficiency in 9 of 46 areas specifically related to bronchoscope handling. These deficiencies as well as proposed mechanisms of damage were highlighted during the lecture feedback session. General bronchoscope handling at various levels of care was routinely critiqued (Table 2).

\section{Discussion}

We present data suggesting that in bronchoscope programs unable to improve repair costs issues internally, the utilization of a MST may help decrease overall institutional repair costs. Previous literature supports significant repair costs associated with high volume

Abbreviated Repair Reduction Evaluation Checklist

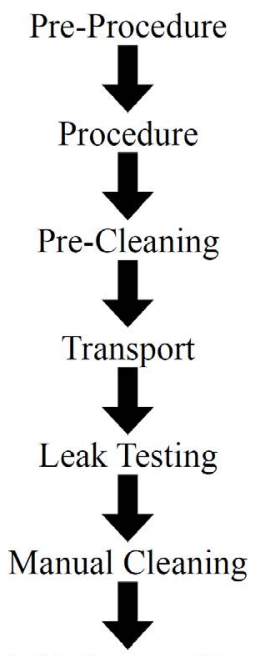

Automatic Endoscope Reprocessor

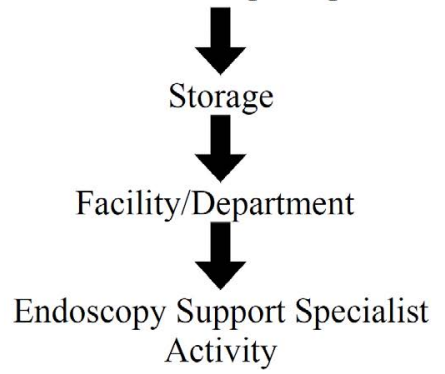

Figure 1: Abbreviated repair reduction evaluation checklist.

\begin{tabular}{|c|c|c|}
\hline & $\begin{array}{c}\text { Pre-intervention } \\
\mathbf{1 0 / 2 0 1 2 - 7 / 2 0 1 3}\end{array}$ & $\begin{array}{c}\text { Intervention } \\
\mathbf{7 / 2 0 1 3 - 3 / 2 0 1 4}\end{array}$ \\
\hline $\begin{array}{c}\text { Bronchoscope repair } \\
\text { costs }\end{array}$ & $\$ 60,015$ & $\$ 19,950$ \\
\hline $\begin{array}{c}\text { Number of repairs }> \\
\$ 1000\end{array}$ & 7 & 3 \\
\hline $\begin{array}{c}\text { Bronchoscope tip related } \\
\text { repairs }\end{array}$ & 7 & 3 \\
\hline
\end{tabular}

Table 1: Damages and costs, before and after intervention.

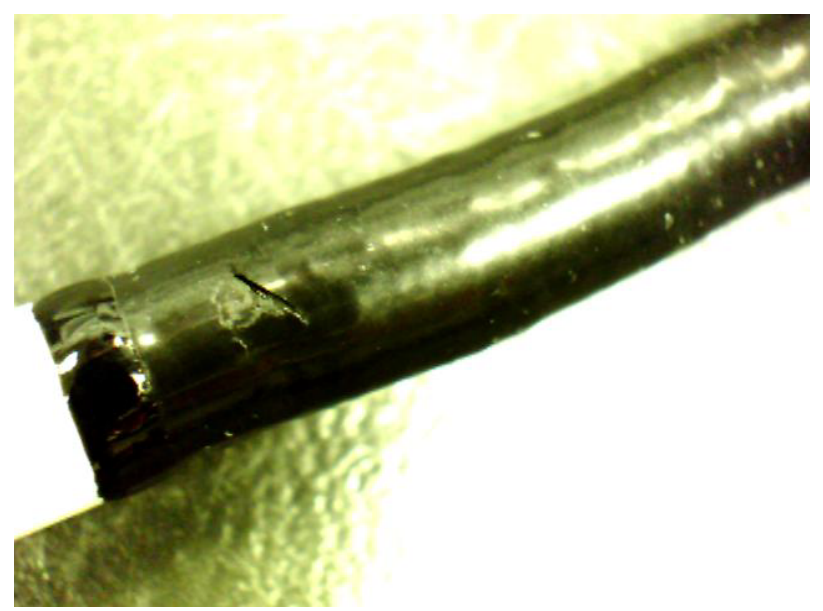

Figure 2: Bending section laceration, possibly from getting caught in a sink drain hole or carrying container made of metal capable of producing a thin slice.

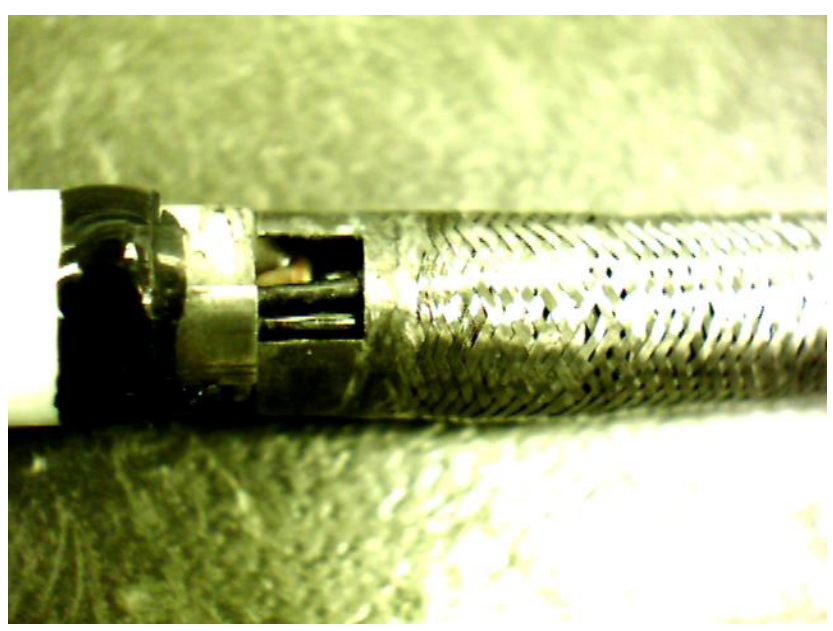

Figure 3: Distal end separation from bending section, occurred when EBUS probe tip was caught on something and pulled by the person handling it.

bronchoscopy programs, ranging from $\$ 10,464-\$ 47,321$ annually [2,4-6]. Manufacturer data (Personal communication, Olympus, Inc.) reports the national average repair cost for flexible and CP-EBUS bronchoscopes are $\$ 73.82$ and $\$ 190.98$ per procedure, respectively, which appear higher than previously cited studies $[2,4,5]$. Our repair costs appear to fair well to these numbers in the intervention period, suggesting we may have been able to attain numbers less than the national average after our intervention.

Previous institutional, internally-based education amongst 
Citation: Kane KP, Toth JW, Reed MF, Gilbert CR (2016) A Novel Intervention to Reduce Bronchoscopy Lab Costs. J Pulm Respir Med 6: 339. doi:10.4172/2161-105X.1000339

Page 3 of 3

\begin{tabular}{|c|c|c|}
\hline Stage of procedure & Witnessed errors & Related repairs \\
\hline $\begin{array}{l}\text { Pre-procedure: } \\
\text { Removal and Transport }\end{array}$ & $\begin{array}{c}\text {-Unsafe handling of bronchoscope with distal end swinging } \\
\text { haphazardly during transport } \\
\text {-Excessive coiling and unnecessary pressure of insertion } \\
\text { tube noted during storage }\end{array}$ & $\begin{array}{l}\text {-Insertion tube damage } \\
\quad \text {-Leaks } \\
\text {-Distal end impact damage }\end{array}$ \\
\hline $\begin{array}{l}\text { Procedure: } \\
\text { Inspection of accessories prior to use }\end{array}$ & $\begin{array}{c}\text {-Accessories (needles, forceps) not inspected prior to each } \\
\text { use }\end{array}$ & $\begin{array}{l}\text {-Biopsy channel damage } \\
\text {-Fluid invasion }\end{array}$ \\
\hline $\begin{array}{l}\text { Transport: } \\
\text { Transport container secure and upright at all times }\end{array}$ & $\begin{array}{l}\text {-Bronchoscope carried by hand to processing room and } \\
\text { placed on floor due to lack of storage room }\end{array}$ & $\begin{array}{l}\text {-Impact/crush damage } \\
\quad \text {-Leaks } \\
\text {-Control knob damage }\end{array}$ \\
\hline $\begin{array}{l}\text { Leak testing: } \\
\text { Proper care/handling during leak testing } \\
\text { Leakage tester inspected prior to use }\end{array}$ & $\begin{array}{l}\text {-Better care could be taken when placing bronchoscope } \\
\text { into sink, distal end care sub-optimal } \\
\text {-Verify leak tester is functioning properly, assure positive } \\
\text { pressure }\end{array}$ & $\begin{array}{c}\text {-Insertion tube buckling } \\
\text {-Leaks } \\
\text {-Missed leaks } \\
\text {-Fluid invasion } \\
\text {-Impact damage }\end{array}$ \\
\hline $\begin{array}{c}\text { Storage: } \\
\text { Bronchoscopes secured away from pinch points }\end{array}$ & $\begin{array}{l}\text {-Sub-optimal handling when placing bronchoscopes into } \\
\text { storage cabinet, distal end swinging freely } \\
\text {-Insertion tube near pinch points in storage cabinets }\end{array}$ & -Impact/crush damage \\
\hline
\end{tabular}

Table 2: Bronchoscope handling critiques and potential damages.

providers and support staff had been pursued for years, and are likely the easiest form of initial review/improvement. Our group remained concerned that further internal review offered potential for team directed blame (clinicians blaming technicians and vice-versa), whereas a third-party, external review would offer an unbiased opinion on everyday practices. We found that the bronchoscope manufacturer's assistance in educating a dedicated bronchoscopy team, and adopting a suite wide campaign of "tip awareness," produced a significant reduction in repair costs. Although the MST team was actively involved in our improvement project to reduce repair costs, and likely provided us with appropriate information to decrease our repair costs, their involvement does clearly present a potential conflict of interest. While they were likely interested in helping us improve the process, so that we remain able to use their product, they also clearly have a financial incentive to drive up repair costs, as they are responsible for repairing their product. We were aware of this phenomenon throughout the process, however feel it did not impact our decisions to implement their suggestions or the ultimate outcomes of the project.

Our study has certain limitations that bear mentioning. First, our retrospective report possesses limitations inherent in study design that must be acknowledged. The identification of high maintenance costs may have sensitized parties of handling and damage issues, resulting in a reduction in damages (regression to the mean phenomenon). However, team members were aware of maintenance cost issues without improvements previously, making this less likely. Second, our study remains based within a single institution; which will limit generalizability and applicability of these results. However, review of the literature notes that flexible endoscope damage occurs in numerous institutions and numerous disciplines, including both gastrointestinal scopes [7] and flexible ureteroscopes [8,9]. An independent report on Olympus flexible ureteroscopes documented that damages commonly involve the distal third of the scope, often requiring replacement of the bending rubber portion, a phenomenon we observed within our cohort, and cited within other bronchoscopy reports [4,5]. Third, many of our bronchoscopy procedures involve trainees, potentially impacting results. However, previous reports imply that trainee involvement does not significantly impact repair costs [4]. Fourth, our observation timeframe remains relatively short, however due to an institutional decision, our program underwent a change in location and staffing at the conclusion of our report, making an adequate analysis and comparison unreasonable after this date.

Maintenance of bronchoscopic equipment remains a costly endeavor. Experienced bronchoscopy suites and team members may be unaware of the best practices in the upkeep and care of these devices. Our intervention demonstrates that product specialists can be utilized to help reduce costs related to bronchoscope damages when internal review and education seem unsuccessful. Further study is needed to help define the sustainability of these interventions and ultimate cost savings.

\section{Funding}

There was no funding available for this study. All authors had access to the final data and manuscript submission. KPK and CRG are the guarantors of the paper from the inception, study design, and manuscript submission.

\section{Author Contributions}

Dr. Kane and Dr. Gilbert participated in data collection, data analysis, manuscript writing, and manuscript review. Dr. Toth and Dr. Reed participated in data analysis, manuscript review.

\section{References}

1. Medford AR, Bennett JA, Free CM, Agrawal S (2010) Endobronchial ultrasound guided transbronchial needle aspiration. Postgrad Med J 86: 106-115.

2. Hergott CA, MacEachern P, Stather DR, Tremblay A (2010) Repair costs for endobronchial ultrasound bronchoscopes. J Bronchology \& Interventional Pulmonology 17: 223-227.

3. Kirkpatrick MB, Smith JR, Hoffman PJ, Middleton RM 3rd (1992) Bronchoscope damage and repair costs: results of a regional postal survey. Respir Care 37 1256-1259.

4. Lunn W, Garland R, Gryniuk L, Smith L, Feller-Kopman D, et al. (2005) Reducing maintenance and repair costs in an interventional pulmonology program. Chest 127: 1382-1387.

5. Rozman A, Duh S, Petrinec-Primozic M, Triller N (2009) Flexible bronchoscope damage and repair costs in a bronchoscopy teaching unit. Respiration 77: 325 330.

6. Mehta AC, Curtis PS, Scalzitti ML, Meeker DP (1990) The high price of bronchoscopy. Maintenance and repair of the flexible fiberoptic bronchoscope. Chest 98: 448-454.

7. Urayama S, Kozarek R, Raltz S (1996) Evaluation of per-procedure equipment costs in an outpatient endoscopy center. Gastrointesinal Endoscopy 44: 129132

8. Sooriakumaran P, Kaba R, Andrews HO, Buchholz NP (2005) Evaluation of the mechanisms of damage to flexible ureteroscopes and suggestions for ureteroscope preservation. Asian J Androl 7: 433-438.

9. Canales BK, Gleason JM, Hicks N, Monga M (2007) Independent analysis of Olympus flexible ureteroscope repairs. Urology 70: 11-15. 